\title{
A New Spore Precipitator with Polarized Dielectric Insulators for Physical Control of Tomato Powdery Mildew
}

\author{
Yoshinori Matsuda, Hiroki Ikeda, Nobuyuki Moriura, Norio Tanaka, Kunihiko Shimizu, Wataru Oichi, \\ Teruo Nonomura, Koji Kakutani, Shin-ichi Kusakari, Katsuhide Higashi, and Hideyoshi Toyoda
}

First to seventh and eleventh authors: Laboratory of Plant Pathology and Biotechnology, Faculty of Agriculture, Kinki University, Nara 6318505, Japan; eighth author: Pharmaceutical Research and Technology Institute, Kinki University, Osaka 577-8502, Japan; ninth author: Agricultural, Food and Environmental Sciences Research Center of Osaka Prefecture, Osaka, 583-0862, Japan; and tenth author: Tsukuba Research Laboratory, Toagosei Co., Ltd., Ibaraki 300-2611, Japan. Accepted for publication 3 April 2006.

\begin{abstract}
Matsuda, Y., Ikeda, H., Moriura, N., Tanaka, N., Shimizu, K., Oichi, W., Nonomura, T., Kakutani, K., Kusakari, S., Higashi, K., and Toyoda, H. 2006. A new spore precipitator with polarized dielectric insulators for physical control of tomato powdery mildew. Phytopathology 96:967-974.

In an attempt to physically protect greenhouse tomato plants from the powdery mildew fungus Oidium neolycopersici, we developed a new electrostatic spore precipitator in which a copper wire conductor is linked to an electrostatic generator and covered with a transparent acrylic cylinder (insulator). The conductor was negatively charged by the generator,

was directly proportional to the potential applied to the conductor and was used to attract conidia of the pathogen. The efficacy of this spore precipitator in protecting hydroponically cultured tomato plants from powdery mildew was evaluated in the greenhouse. The hydroponic culture troughs were covered with a cubic frame installed with the spore precipitator, and the disease progress on precipitator-guarded and unguarded seedlings was traced after the conidia were disseminated mechanically from inoculum on tomato plants. Seedlings in the guarded troughs remained uninfected during the entire experiment, in spite of rapid spread of the disease to all leaves of the unguarded seedlings.
\end{abstract} and the electrostatic field created by the conductor was used to dielectrically polarize the insulator cylinder. The dielectrically polarized cylinder also produced an electrostatic force without a spark discharge. This force
Additional keyword: Lycopersicon esculentum.
The powdery mildew pathogen of greenhouse tomato, causing severe damage worldwide, produces fibrosin body-free conidia singly $(11,17,35,36,38,41)$, in short chains $(1,15,32,37,42)$, or a combination of the two $(2,8,12,39)$. Cleistothecia have never been described for this powdery mildew fungus. Kiss et al. (16) reported that all recent outbreaks of tomato powdery mildew outside Australia were caused by a species that formed conidia singly or, occasionally, in pseudochains of two to six conidia in high relative humidity, and proposed that a new species, Oidium neolycopersici, be erected, provided that the Australian isolates that always formed conidia in chains retained the name $O$. lycopersici.

In Japan, a pathogen similar to tomato powdery mildew was found (23) and identified as a Japanese isolate of O. neolycopersici (KTP-01) (13). The causal pathogen severely infected not only all commercial cultivars tested, but also the cultivars bred for resistance against a European isolate of the pathogen (14). In our preliminary survey, we found fungicide-tolerant isolates of $O$. neolycopersici on naturally infected tomato leaves, indicating the necessity for alternative measures to control the pathogen. Although breeding resistant traits against the pathogen has been the conventional method to protect crop plants from the disease $(6,21,22,27,40)$, we should always be alert for the outbreak of new pathogenic strains of the pathogen on newly bred resistant tomato lines $(3,19,24)$. Thus, we have developed new physical control measures to prevent the spread of the disease.

Uncharged particles can be dielectrophoretically moved by virtue of an induced dipole in a nonuniform electric field; the dipole

Corresponding author: H. Toyoda; E-mail address: toyoda@nara.kindai.ac.jp

DOI: 10.1094/PHYTO-96-0967

(C) 2006 The American Phytopathological Society develops a negative charge at one end and an equal and opposite positive charge at the other end (7). Cell walls of bacteria, yeast, and plants act as electrical conductors under the influence of an electric field (29). When a polarized dielectric insulator is brought into contact with the cells, the negative surface charge of the insulator causes free electrons to move within the cell walls to produce a dipolar charge (electrostatic induction), with a positive charge on the side of the insulator and a negative charge on the opposite side $(9,10,29)$. In our previous work $(30,31)$, fungal spores were electrostatically attracted by the surface charge of the negatively polarized insulators. Thus, the electrostatic force between these spores and a polarized insulator could be used to collect airborne spores. This technique fundamentally differs from conventional electrostatic precipitation methods to collect airborne microorganisms that are aerosolized by spray ionizing agents $(20,28)$.

In the present study, we describe an electrostatic spore precipitator which has a negatively charged copper wire coaxially surrounded by a transparent acrylic cylinder. The precipitator attracts conidia via the surface charge of the polarized dielectric cylinders that are electrostatically activated by the negatively charged inner wire. Using this system, we protected hydroponically grown tomato plants from powdery mildew in the greenhouse.

\section{MATERIALS AND METHODS}

Pathogen and plants. Conidia of $O$. neolycopersici KTP-01 (13) and cvs. Moneymaker and Micro-Tom of tomato (Lycopersicon esculentum Mill) were used. These two cultivars are highly susceptible to KTP-01 (24). Germinated seed of Moneymaker were sown in vermiculite in a tray, and 10-day-old seedlings were transplanted into soil in $15-\mathrm{cm}$ pots. The plants were grown in a propagation greenhouse for 20 days, then transferred to an 
inoculation greenhouse controlled at $25 \pm 3^{\circ} \mathrm{C}$. The conidia were maintained on leaves of 1-month-old seedlings of Moneymaker according to the method described previously (13). Newly produced conidia of 8-day-old powdery mildew colonies on leaves were used for subsequent experiments. The conidia were dusted by tapping or brushing colony-forming leaves for inoculation.

Electrostatic spore precipitator. A straight copper wire $(2 \mathrm{~mm}$ in diameter) was used as the conductor and a transparent acrylic cylinder $(10 \mathrm{~mm}$ in diameter and 1 or $1.5 \mathrm{~m}$ in length) insulated the wire. Insulating silicon stoppers at the middle and both ends of the cylinder held the copper wire in place as it passed through the cylinder (Fig. 1A). The cylinders were linked in parallel, and the wire end was connected to the electrostatic generator. The wire was negatively charged by the electrostatic generator, and the electrostatic field created by the charged wire dielectrically polarized the cylinder (positive on the inner surface, negative on the outer surface) (Fig. 1B). The electrostatic force produced by the dielectrically polarized cylinder was used to attract the conidia in the air. The level of static electricity on the outer surface was controlled by changing the voltage (between 5 and $50 \mathrm{kV}$ ) supplied to the wire. The potential difference $(\mathrm{kV})$ on the outer surface of the cylinder was measured with an electrostatic field meter FMX-002 (Simco, Kobe, Japan), and the spark discharge (nC) from the outer surface was measured with a probe $(50-\mu \mathrm{m}$ tip diameter) on a coulombmeter NK-1001 (Kasuga Denki, Tokyo). The potential applied to the wire was kept at $30 \mathrm{kV}$ to provide a potential difference on the outer surface of the cylinder that would not discharge a spark.

Spore attraction test. To determine proper operational conditions which would attract conidia, a single spore precipitator was placed at different distances from the conidia-dusting site (Fig. $2 \mathrm{~A}$ ), and different voltages ( 5 to $30 \mathrm{kV}$ ) were applied. The leaves serving as an inoculum source were held at the top of a transparent acrylic channel and gently tapped to drop the conidia from leaves through the channel (Fig. 2A). The polarized dielectric cylinder was gradually brought to the conidia-dusting site while the cylinder surface was viewed with a zoom lens MX-2525CS $(\times 250$ to $\times 2,500$ ) of a high-fidelity digital microscope KH-2700 (Hirox, Tokyo). The distance at which the conidia were first attracted to the cylinder was recorded as a possible limit for the attractive force. The digital microscopic observation was conducted by the method described previously (31). Successful attraction of conidia to the cylinder was confirmed by checking that no conidia were deposited on glass slides below the conidium-dusting site.

The best spacing between cylinder surfaces was determined by testing for successful trapping of the dropped conidia. Between 14 and 33 cylinders were oriented in parallel in a horizontal plane $40 \mathrm{~cm}$ above the floor to obtain different spacings (10 to $70 \mathrm{~mm})$ between the cylinders, and a rectangular cardboard channel was set on the cylinders (Fig. 3A). The cylinders then were dielectrically polarized with a particular voltage level, and detached tomato leaves with conidia-forming powdery mildew colonies were placed on a stainless steel mesh on the top of the channel. In all, 200 glass slides were laid on the floor beneath the precipitator to collect the conidia passing through the cylindrical array. The conidia attracted to the cylinders and dropping onto glass slides were observed directly with the digital microscope 10 min after dusting, according to the method described previously (31).

In the third experiment, the spore precipitator $(60-\mathrm{mm}$ cylinder interval, $30-\mathrm{kV}$ applied voltage) was tested for its trapping ability under a mechanical blower. In total, 42 cylinders were installed on two opposite vertical faces of the cubic frame and placed in the end of a rectangular acrylic tunnel (Fig. 3B). Five uninfected tomato plants were placed in the frame and three inoculum plants (with sporulation on all leaves) were placed in the tunnel, $1 \mathrm{~m}$ upstream from the cubic frame. An electric fan was placed at the opposite entry end of the tunnel, and the wind was blown continuously at different velocities (between 0.1 and $1.0 \mathrm{~m} / \mathrm{s}$ ) toward the cubic frame over the inoculum plants for $1 \mathrm{~h}$ at each specified velocity. The wind velocity was measured at the site of the cylinders using an anemometer (testo-425; Testoterm, Lenzkirch, Germany).

The appearance of the fungal colonies on the leaves of the plants in the cubic frame was examined 10 days later. Disease incidence was expressed as the percentage of leaves with at least one powdery mildew colony. Data are expressed as means and standard errors of three replications. A control experiment was conducted similarly using nonelectrified cylinders.

Effect of conidial precipitators on disease under greenhouse conditions. Tomato plants, cv. Micro-Tom, were hydroponically

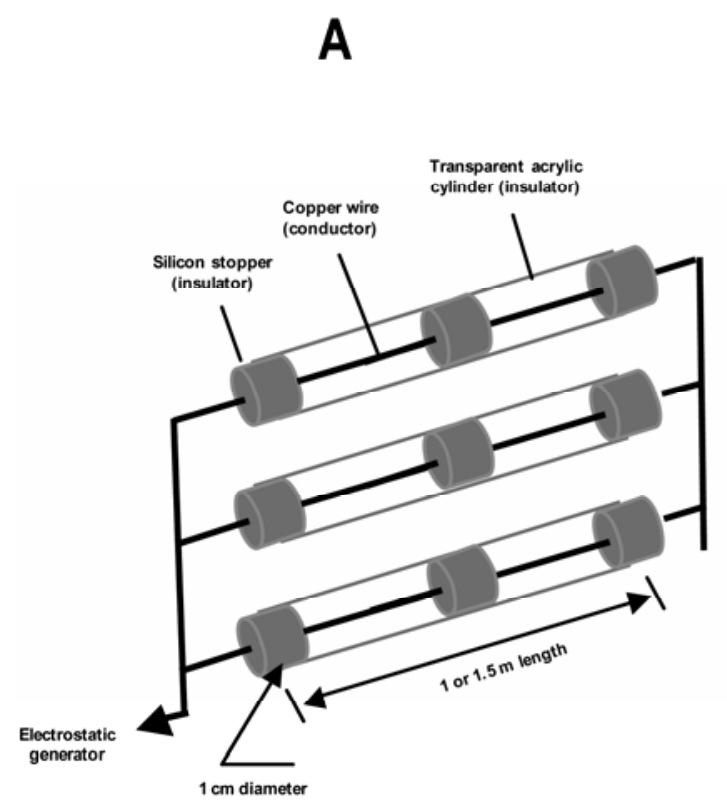

B

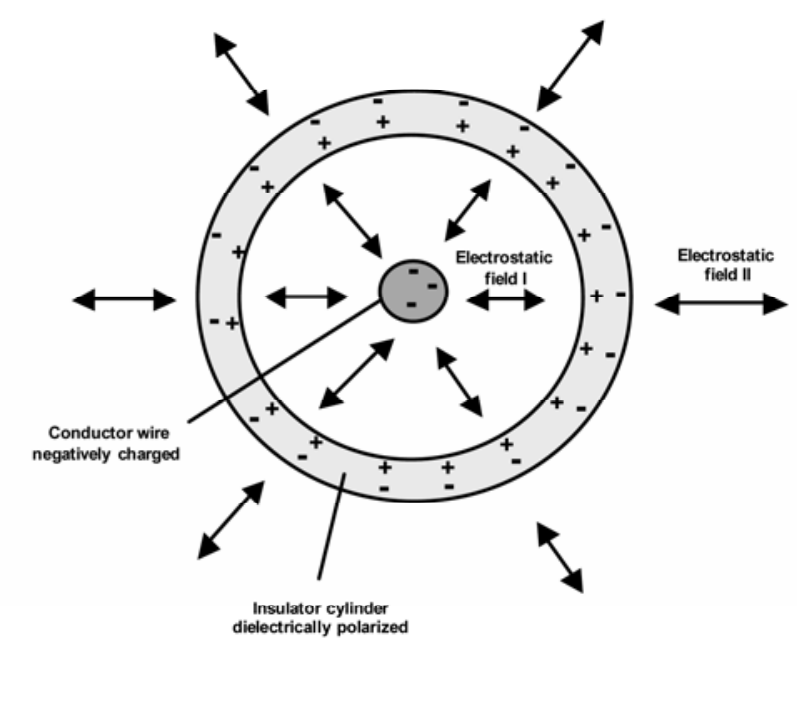

Fig. 1. Schematic representation of the spore precipitator devised in the present study. A, Copper wire (conductor) covered with a transparent acrylic cylinder (insulator) and held at the middle and both ends of the cylinder with insulating silicon stoppers. The cylinders were linked in parallel. The copper wire was negatively charged by an electrostatic generator. B, Possible mode of dielectric polarization of the insulator cylinder by an electrostatic field (I) produced by the negatively charged copper wire. The polarized dielectric cylinder produces an electrostatic field (II) to cause the dipole on the conidia. 
cultured (34) to test the feasibility of the spore precipitator to protect plants under greenhouse conditions. Germinated seed were placed in polyurethane sponge supports ( 3 by 3 by $3 \mathrm{~cm}$ ) soaked in a hydroponic nutrient solution and grown in a propagation greenhouse $\left(26 \pm 2{ }^{\circ} \mathrm{C}\right)$ for 3 weeks. The seedlings were transferred to hydroponic culture troughs in the inoculation greenhouse and cultured for one more week. During the experiment, the culture solution (120 liters) was circulated with a flow rate of 2 liters/min, and a constant regulation of $\mathrm{pH}(6.0$ to 6.5$)$ and electrical conductivity $(1.2 \mathrm{mS} / \mathrm{cm})$. Three hydroponic culture troughs (single trough, 0.9 by $1.2 \mathrm{~m}$ ) were used as one unit for the experiment. The central trough was covered with the cubic frame having a total of 120 spore precipitation cylinders $(60-\mathrm{mm}$ cylinder interval, 30-kV applied voltage) (Fig. 4A). Thirty seedlings
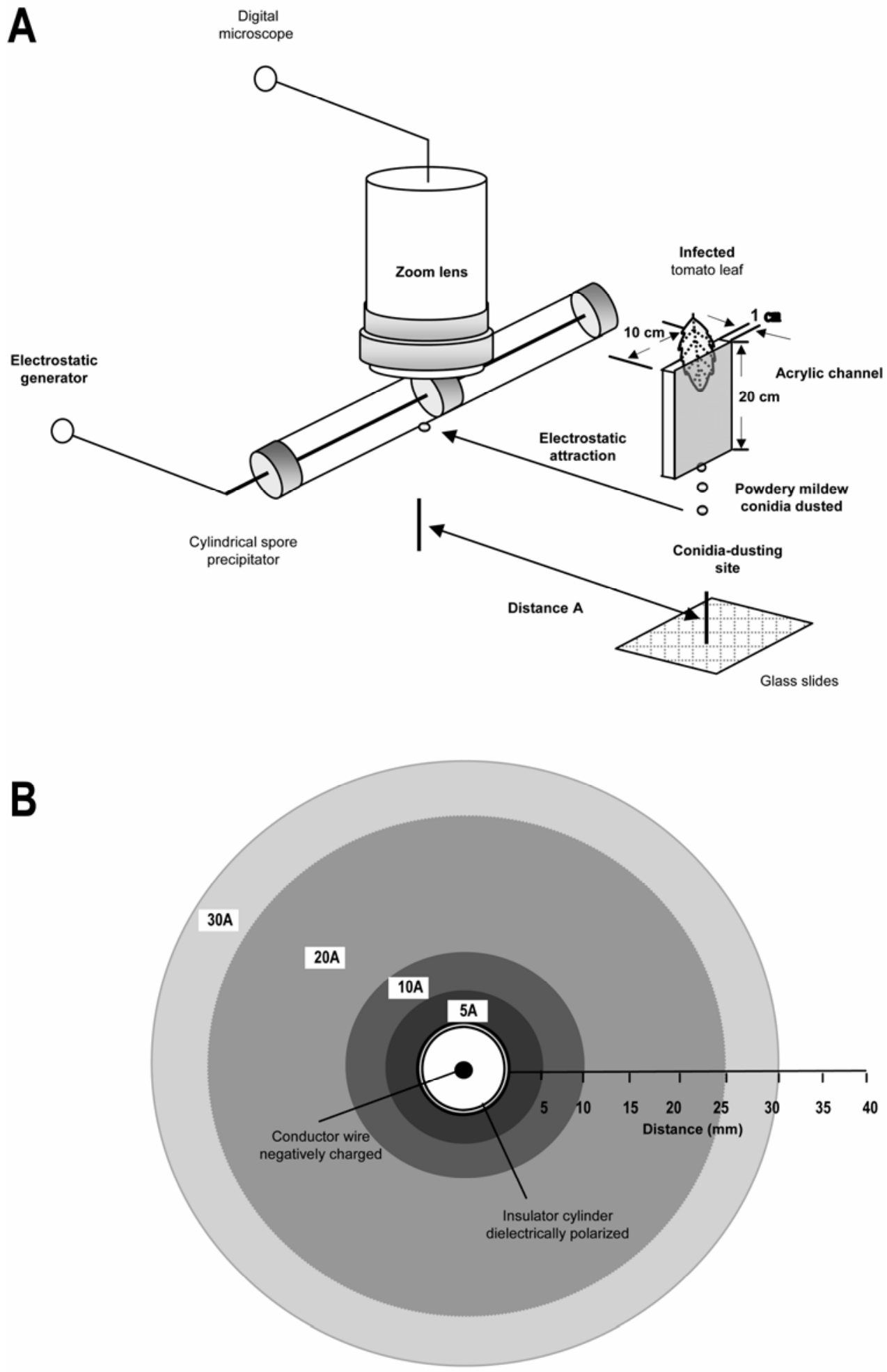

Fig. 2. Electrostatic attraction of conidia of Oidium neolycopersici tapped from infected tomato plants using the cylindrical spore precipitator. A, Schematic diagram for testing the conidium-attractive distance of the polarized dielectric cylinder against the conidia dropped from the infected tomato leaf at the dusting site. The cylinder was gradually brought to the inoculum site while viewing with a high-fidelity digital microscope to determine a conidium-attractive distance (distance A). B, The conidium-attractive area around the polarized dielectric cylinder. The areas 5A to 30A represent the conidium-attractive ranges produced by wire potentials of 5 to $30 \mathrm{kV}$, respectively. 
(six plants per row and five rows) were grown in each hydroponic culture trough. For inoculation, three KTP-01-inoculated tomato plants (2-month-old seedlings) producing abundant conidia on leaves were placed $5 \mathrm{~m}$ in front of both guarded and unguarded troughs, and the conidia were disseminated from the leaves by an electric fan $(1.0 \mathrm{~m} / \mathrm{s}$ wind velocity) during the entire period of the experiment (for 21 days). Appearance of disease symptoms and signs on leaves of test plants was recorded daily for 3 weeks. Disease incidence of test plants was determined as described earlier, and data are stated as means and standard errors of three replications.

In the second experiment, a single inoculated plant (1-monthold seedling inoculated with KTP-01) was placed in the center of a frame-covered hydroponic trough with 30 healthy plants. The spread of the conidia to the noninoculated seedlings in the same hydroponic culture trough or in the next uncovered trough was monitored for 3 weeks after colonies first appeared on leaves of the first seedlings inoculated. At the end of the experiment, the conidia on the leaves or on the cylinder of the spore precipitator were observed using the high-fidelity digital microscope as described previously (25).

\section{RESULTS}

Between 5 and $30 \mathrm{kV}$ could be applied without discharging a spark from the outside of the cylinders. Within this permissible range, the area of conidium attraction was concentrically in proportion to the voltage applied to the conductor wire. The potential conidium attractive regions around the cylinder under different voltage conditions are shown diagrammatically in Figure $2 \mathrm{~B}$. The
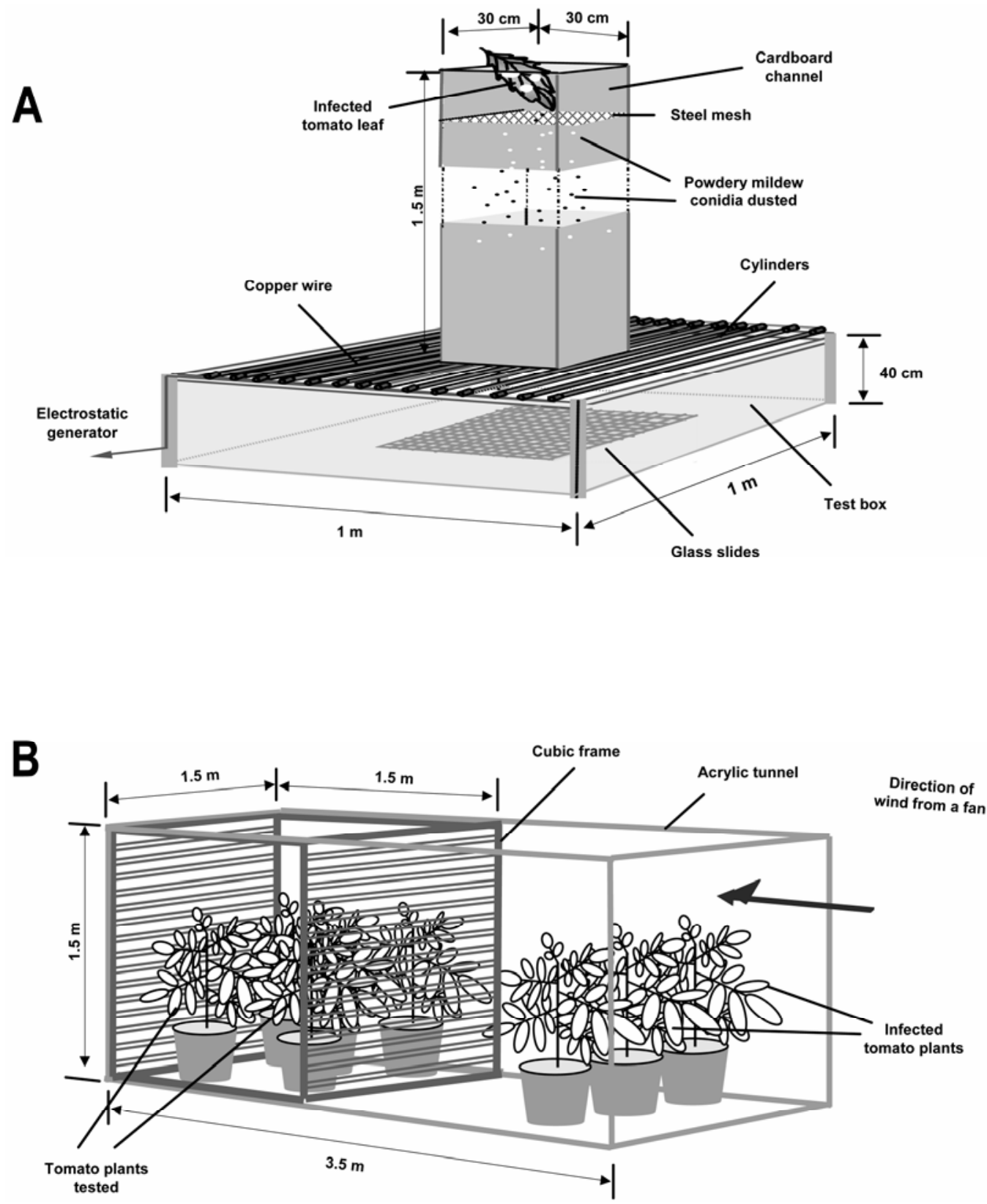

Fig. 3. Schematic representation of experimental setups for testing attraction of Oidium neolycopersici conidia using the cylindrical spore precipitator. A, Between 14 and 33 cylinders were oriented in parallel on the roof of a test box, and a cardboard channel was placed on the cylinders. A copper wire in the cylinders was negatively charged with voltages ranging from 5 to $30 \mathrm{kV}$. Inoculum leaves were placed on a stainless mesh on the top of a cardboard channel to supply conidia. The conidia deposited onto a total of 200 glass slides laid on the floor or attracted to the cylinders were observed directly with a high-fidelity digital microscope. B, In all, 42 cylinders (with 60-mm spacing) were attached to the vertical faces of the frame set in the acrylic tunnel. A copper wire was negatively charged with $30 \mathrm{kV}$. Conidia of inoculum plants were mechanically blown for $1 \mathrm{~h}$ at 0.1 or $1.0 \mathrm{~m} / \mathrm{s}$. The appearance of disease symptoms and signs in test plants was examined 10 days after inoculation. 
spore precipitator attracted conidia that were, at most, $30 \mathrm{~mm}$ from the cylinder. These data were useful to determine the widest spacing between the parallel cylinders in the spore precipitator.

Using the spore precipitator at different cylinder spacings, we confirmed the successful attraction of the dropped conidia (Table 1). At all voltages, the widest cylinder spacing was held at twice the conidium-attractive distance determined in Figure 2B. With the optimal distance between the cylinders, the spore precipitator completely prevented the dusted conidia from passing through the gap between the cylinders. At the highest useful voltage $(30 \mathrm{kV})$, the maximum spacing between the cylinders was $60 \mathrm{~mm}$.

Using the blower at different wind velocities, we tested the attraction of the conidia by the spore precipitator with the widest spacing between the cylinders $(60-\mathrm{mm}$ cylinder interval; $30-\mathrm{kV}$ applied voltage). The test plants in the precipitator-installed frame remained uninfected even when the conidia were blown by the strongest wind $(1.0 \mathrm{~m} / \mathrm{s})$, whereas fungal colonies formed on almost all leaves of the test plants when the spore precipitator was not electrified (Fig. 5).

To evaluate the practicality of the spore precipitator, MicroTom tomato seedlings were transferred to hydroponic culture troughs that were either fitted or not fitted with the polarized dielectric cylinders in the greenhouse. On seedlings in the unguarded troughs, fungal colonies first appeared on leaves 3 to 4 days after the inoculum plants were placed in the same greenhouse, then spread to the young upper leaves that developed later
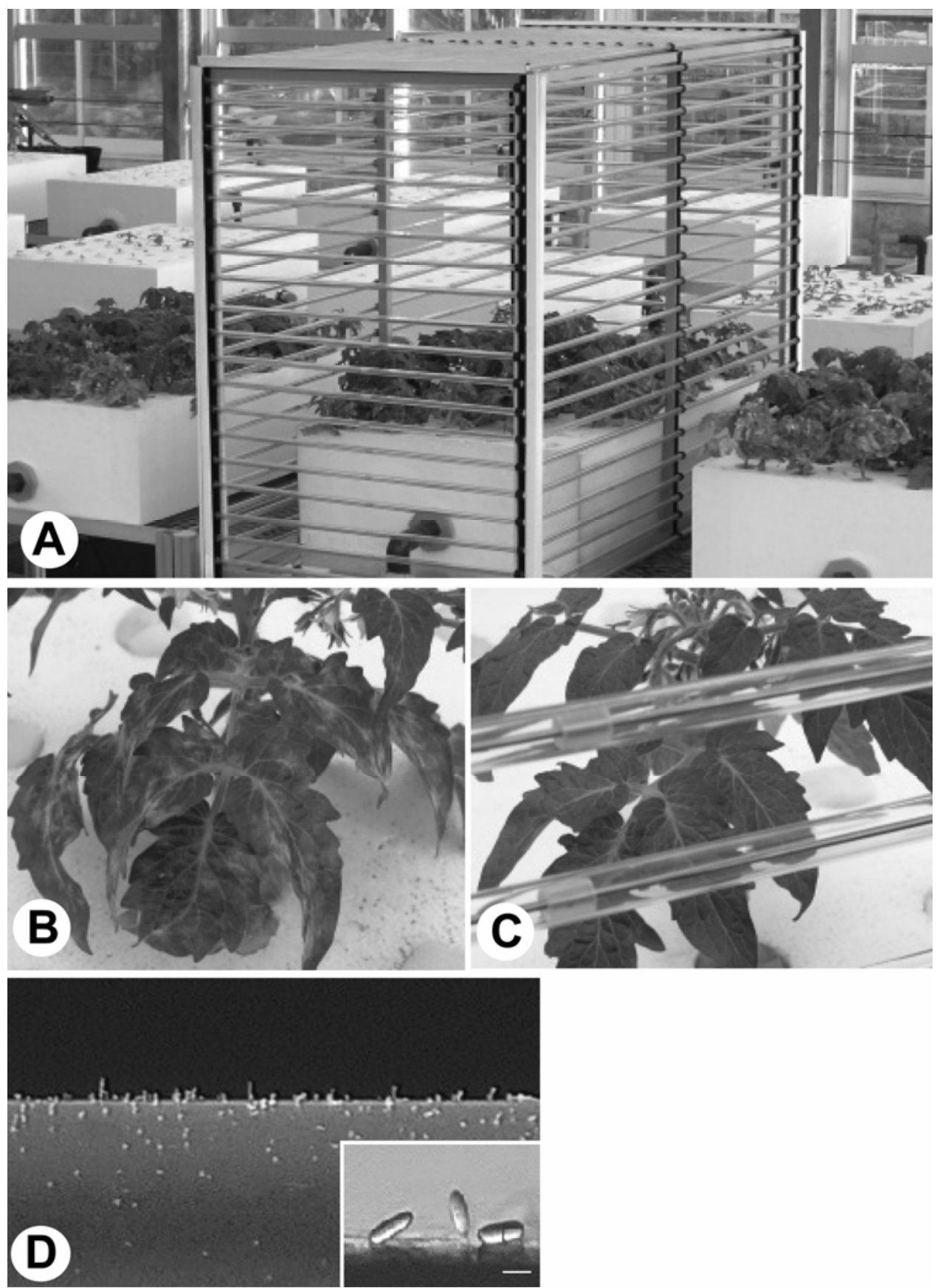

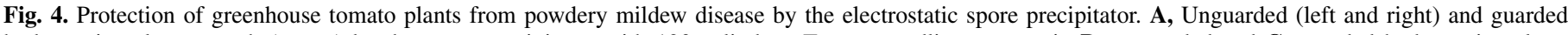

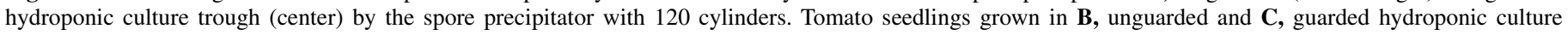

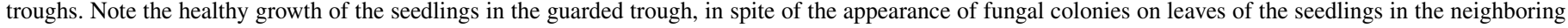

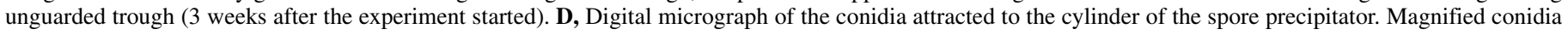
shown in the inserted micrograph. Bar represents $10 \mu \mathrm{m}$. 
TABLE 1. Electrostatic collection of Oidium neolycopersici conidia with a cylindrical spore precipitator ${ }^{\mathrm{a}}$

\begin{tabular}{|c|c|c|c|c|c|c|c|c|c|c|c|c|c|c|}
\hline \multirow[b]{3}{*}{ Voltage $^{b}$} & \multicolumn{14}{|c|}{ Spacing between the cylinders $(\mathrm{mm})^{\mathrm{c}}$} \\
\hline & \multicolumn{2}{|c|}{10} & \multicolumn{2}{|c|}{20} & \multicolumn{2}{|c|}{30} & \multicolumn{2}{|c|}{40} & \multicolumn{2}{|c|}{50} & \multicolumn{2}{|c|}{60} & \multicolumn{2}{|c|}{70} \\
\hline & Slides & Cylinders & Slides & Cylinders & Slides & Cylinders & Slides & Cylinders & Slides & Cylinders & Slides & Cylinders & Slides & Cylinders \\
\hline 0 & 2,438 & 3,700 & 5,320 & 2,932 & 6,732 & 2,653 & 4,640 & 3,201 & 6,214 & 2,250 & 6,621 & 1,825 & 7,534 & 1,250 \\
\hline 5 & 0 & 7,140 & 312 & 10,500 & 420 & 7,570 & 941 & 8,841 & 1,310 & 7,606 & 846 & 4,237 & 1231 & 6,460 \\
\hline 10 & 0 & 9,550 & 30 & 9,420 & 365 & 7,710 & 863 & 9,010 & 503 & 6,984 & 451 & 5,911 & 431 & 4,385 \\
\hline 20 & 0 & 9,560 & 0 & 8,280 & 0 & 7,780 & 0 & 6,401 & 0 & 7,691 & 3 & 6,900 & 16 & 5,474 \\
\hline 30 & 0 & 14,460 & 0 & 7,240 & 0 & 7,350 & 0 & 6,490 & 0 & 5,419 & 0 & 5,230 & 3 & 6,121 \\
\hline
\end{tabular}

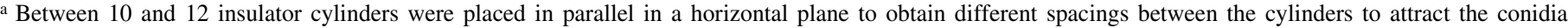
dropped from infected tomato leaves.

b Voltage $(-\mathrm{kV})$ applied to inner copper wire.

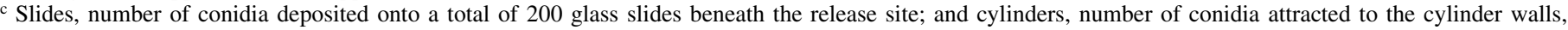
which were observed with a digital microscope.

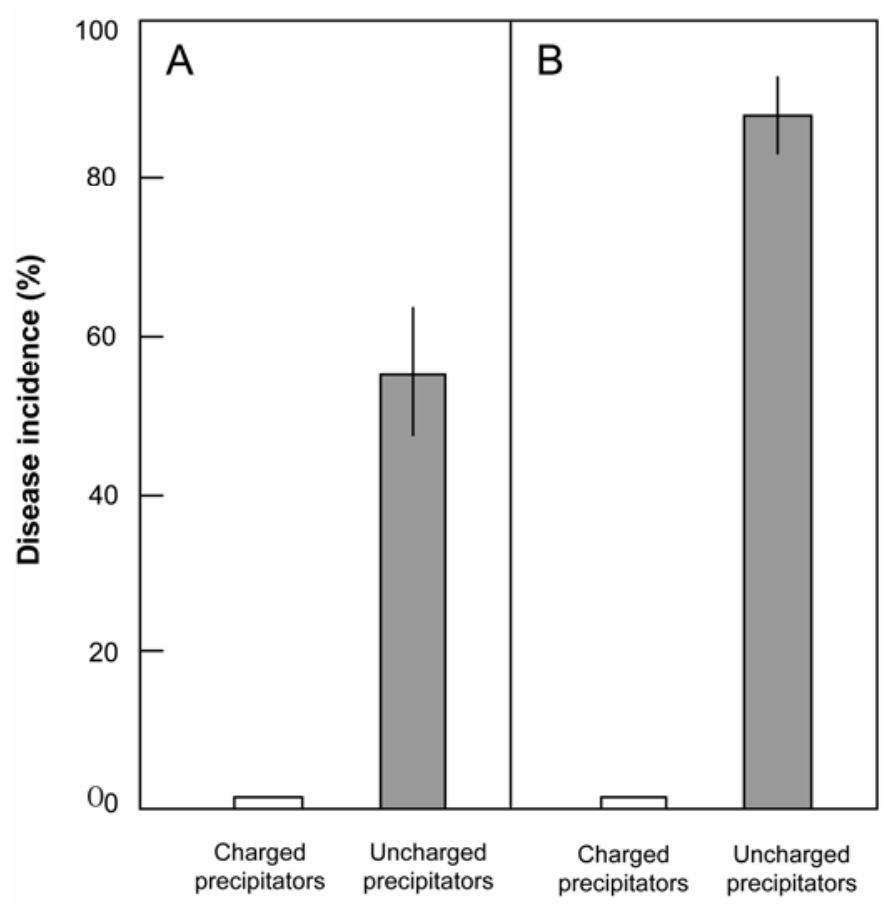

Fig. 5. Electrostatic attraction of Oidium neolycopersici conidia under wind conditions of $\mathbf{A}, 0.1$ and $\mathbf{B}, 1.0 \mathrm{~m} / \mathrm{s}$. Test plants were placed in the box installed with charged and uncharged cylindrical precipitators $(60-\mathrm{mm}$ spacing between cylinder surfaces), and conidia of inoculum plants were blown for $1 \mathrm{~h}$ by an electric fan. Disease incidence was expressed as the percentage of leaves with at least one powdery mildew colony 10 days after inoculation. Data are means and standard errors of three replications.

(Fig. 6A). Eventually, almost all leaves of all unguarded seedlings were infected with the pathogen during the 3-week experiment (Fig. 4B). On the other hand, the seedlings in the guarded troughs remained uninfected throughout the experiment (Figs. 4C and 6A and B). By direct microscopic observation of the leaves or the cylinder surface, we confirmed that all leaves of the cylinderguarded seedlings were free of conidia and that numerous conidia had been attracted to the cylinder surface (Fig. 4D). These results indicate that the spore precipitator successfully prevented the entry of the conidia into the guarded hydroponic culture trough.

Moreover, the spore precipitator also was effective in preventing the dissemination of the conidia on the leaves of seedlings in the cylinder-guarded trough to the seedlings outside. In the cylinder-guarded hydroponic trough where the inoculum plants were placed, the disease spread to all seedlings from the inoculum plants within 3 weeks. However, the seedlings in the neighboring trough remained healthy, even after the conidia were shaken from infected leaves of the seedlings in the guarded trough (Fig. 6C and D).

\section{DISCUSSION}

Here, we used an electrostatic force to successfully and effectively attract powdery mildew conidia disseminated from infected tomato leaves. Leach (18) described that many wind-dispersed fungal spores are violently ejected into the atmosphere and become electrically charged at the instant of release. McCartney et al. (26) calculated the surface charge of the conidia impacted into charged cylinders, but the charge was too low to influence deposition onto natural surfaces. In our previous report (31), we showed that conidia of the barley powdery mildew fungus (Blumeria graminis f. sp. hordei) were attracted either to negatively or positively polarized insulators, implying that the charge on the conidia was negligible. In the highly divergent electric field around a polarized dielectric cylinder, a dipole develops on the conidia as a result of the field (7); thus, the electrostatic attraction between the conidia and cylinder surface is likely to be what attracts the conidia in the air.

The negatively charged conductors also create an electrostatic attraction. At the same time, however, in initial experiments, these electrified conductors transferred the negative electricity to the surrounding plants through a spark discharge (data not shown). The strength of the spark discharge was inversely proportional to increasing distance from the plants, especially when the plants were growing in soil, because the transferred charge was easily released to the ground. In our cultivation system, the pipes of the hydroponic culture apparatus also were grounded. The repeated spark discharge caused serious damage to neighboring plants: leaf yellowing, necrosis, and, in extreme cases, withering of the entire plant. From a practical viewpoint, shielding of the conductor was essential to minimize this harmful discharge. In the spore precipitator presented here, the wire conductor was shielded with the cylindrical insulator, and the electrostatic force created by the conductor was used to dielectrically polarize the insulator without discharging a spark.

The spore precipitator worked effectively when the spacing between the cylinders and the voltage applied to the conductor wire were optimized to attract conidia that were mechanically blown off the plants toward the precipitator. In greenhouse conditions, spore attraction in our system was so satisfactory that the precipitator-guarded plants remained uninfected throughout the entire experiment. Under these conditions, the precipitator-installed trough was exposed continuously to wind $(1.0 \mathrm{~m} / \mathrm{s}$ velocity) from an electric fan. The wind velocity was higher than the air stream $(0.4$ to $0.8 \mathrm{~m} / \mathrm{s})$ produced by the ventilator in the greenhouse. The result suggests that the spore precipitator can be used to trap conidia in a well-ventilated greenhouse.

Some investigators have reported that nongerminated conidia of the barley powdery mildew fungus secreted sticky substances immediately after they attached to a leaf or artificial surface $(4,5,33,43)$. Conidia of $O$. neolycopersici also became sticky from their rapid secretion of a substance within $3 \mathrm{~min}$ of the attraction 


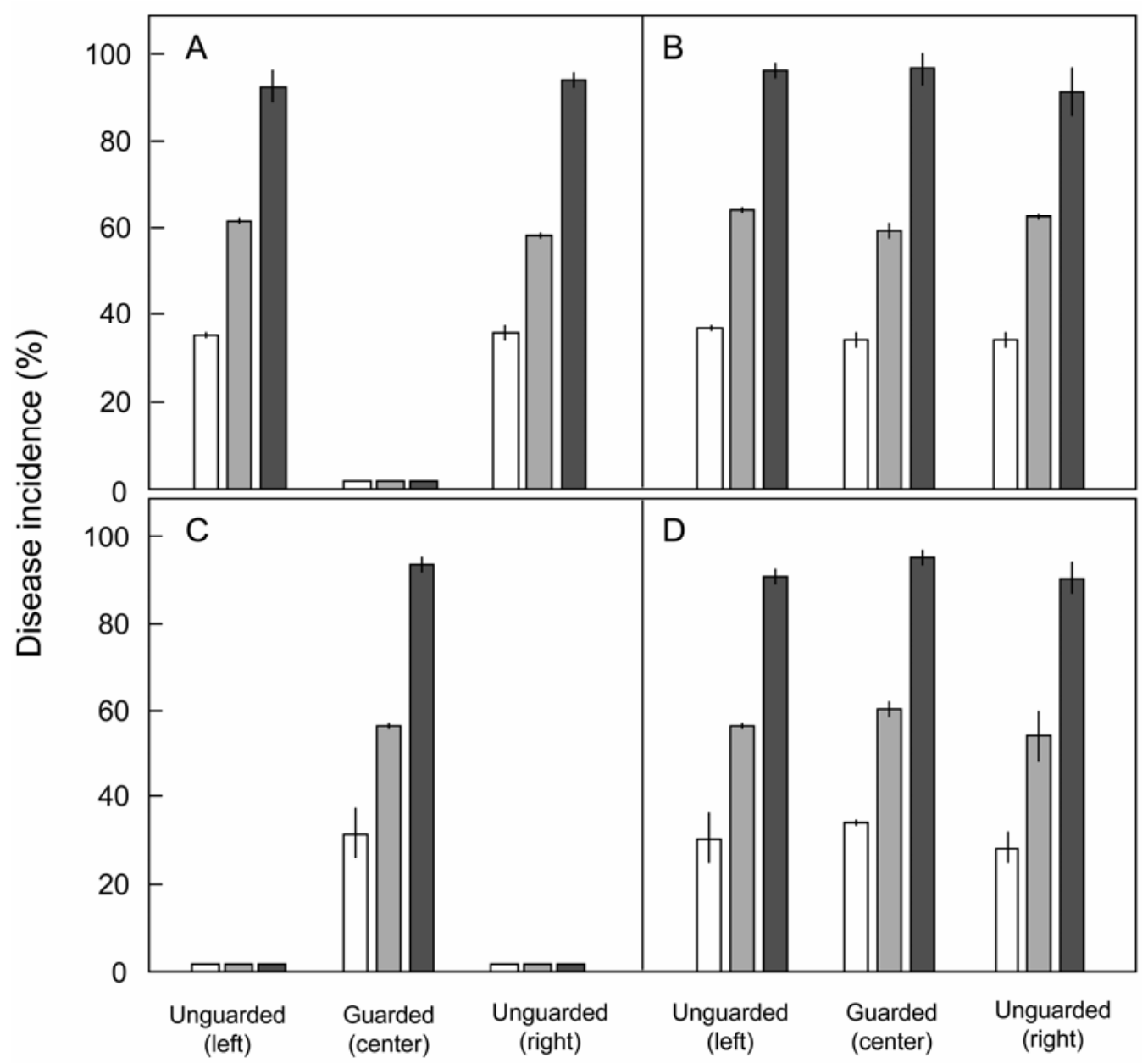

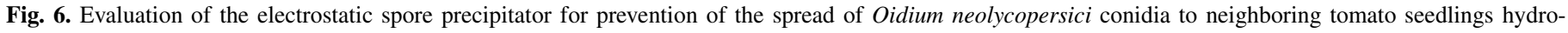

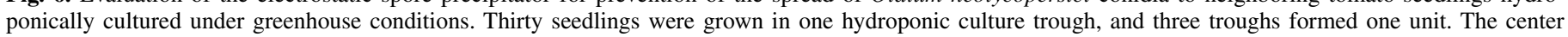

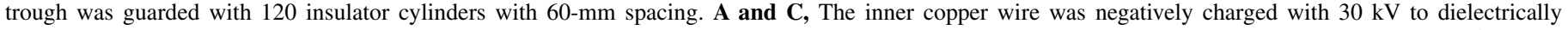

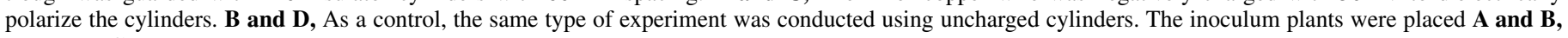

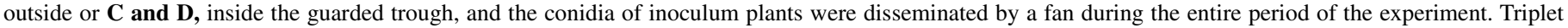

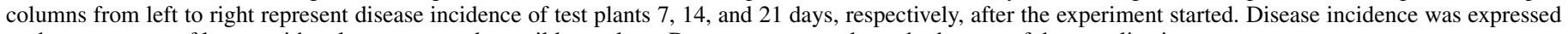
as the percentage of leaves with at least one powdery mildew colony. Data are means and standard errors of three replications.

to the cylinder surface (data not shown). The secretion of the sticky substance by the conidia on the surface of the insulator is another factor that contributes to attachment of the conidia to the spore precipitator.

The present work was designed to describe the structure of the proposed electrostatic spore precipitator and the physical principle of operation. The use of this spore precipitator effectively prevents susceptible plants from becoming exposed to inoculum and is likely to lead to a reduction in the use of chemical fungicides. This should be more acceptable to the public as a physical protection for high-value crop plants. We are in the process of developing the spore precipitator for practical, commercial application. By our calculations, 5,000 cylinders would be necessary to entirely cover four culture beds $\left(1.5 \times 18 \mathrm{~m}^{2}\right)$ in a typical Japanese greenhouse $\left(10 \times 20 \mathrm{~m}^{2}\right)$. The windows of a greenhouse are the most important sites for the spore precipitator; thus, a prototype window blind-shape spore precipitator was made as a working model using an acrylic plate in which an aluminum film (conductor) was embedded (data not shown). The spore precipitator can be activated automatically at the time of window opening. This automated approach is useful not only to prevent the entry of the pathogen into the greenhouse, but also to reduce the running cost of the spore precipitator.

The spore precipitator described in this study is easy to construct; hence, mass production is possible on a commercial scale.
The cost can be reduced further by using cheaper insulating materials. We used a transparent insulator to minimize shading by the cylinders, but other insulator-shielded conductors are similarly available.

\section{ACKNOWLEDGMENTS}

We thank B. E. Hazen for helpful comments and suggestions to revise the manuscript.

\section{LITERATURE CITED}

1. Arredondo, C. R., Davis, R. M., Rizzo, D. M., and Stahmer, R. 1996. First report of powdery mildew of tomato in California caused by an Oidium sp. Plant Dis. 80:1303.

2. Bélanger, R. R., and Jarvis, W. R. 1994. Occurrence of powdery mildew (Erysiphe sp.) on greenhouse tomatoes in Canada. Plant Dis. 78:640.

3. Brown, J. K. M. 2002. Comparative genetics of avirulence and fungicide resistance in the powdery mildew fungi. Pages 56-65 in: The Powdery Mildews. R. R. Bélanger, W. R. Bushnell, A. J. Dik, and T. L. W. Carver, eds. The American Phytopathological Society, St. Paul, MN.

4. Carver, T. L. W., Kunoh, H., Thomas, B. J., and Nicholson, R. L. 1999. Release and visualization of the extracellular matrix of conidia of Blumeria graminis. Mycol. Res. 103:547-560.

5. Carver, T. L. W., Thomas, B. J., and Ingerson-Morris, S. M. 1995. The surface of Erysiphe graminis and the production of extracellular material at the fungus-host interface during germling and colony development. Can. J. Bot. 73:272-287. 
6. Ciccarese, F., Amenduni, M., Schiavone, D., and Cirulli, M. 1998. Occurrence and inheritance of resistance to powdery mildew (Oidium lycopersici) in Lycopersicon species. Plant Pathol. 47:417-419.

7. Cross, J. A. 1987. Dielectrophoresis. Pages 269-276 in: Electrostatics: Principles, Problems and Applications. A. E. De Barr, ed. Adam Hilger, Bristol, UK.

8. Fletcher, J. T., Smewin, B. J., and Cook, R. T. A. 1988. Tomato powdery mildew. Plant Pathol. 37:594-598.

9. Griffith, W. T. 2004. Electrostatic phenomena. Pages 232-252 in: The Physics of Everyday Phenomena, A Conceptual Introduction to Physics. D. Bruflodt and B. S. Loehr, eds. McGraw Hill, New York.

10. Halliday, D., Resnick, R., and Walker, J. 2002. Electric charge. Pages 505-519 in: Fundamentals of Physics. S. Johnson and E. Ford, eds. John Wiley \& Sons, New York.

11. Jones, H. E., Whipps, J. M., Thomas, B. J., Carver, T. L. W., and Gurr, S. J. 2000. Initial events in the colonisation of tomatoes by Oidium lycopersici, a distinct powdery mildew fungus of Lycopersicon species. Can. J. Bot. 78:1361-1366.

12. Karasevicz, D. M., and Zitter, T. A. 1996. Powdery mildew occurrence on greenhouse tomato plants in New York. Plant Dis. 80:709.

13. Kashimoto, K., Matsuda, Y., Matsutani, K., Sameshima, T., Kakutani, K., Nonomura, T., Okada, K., Kusakari, S., Nakata, K., Takamatsu, S., and Toyoda, H. 2003. Morphological and molecular characterization for a Japanese isolate of tomato powdery mildew Oidium neolycopersici and its host range. J. Gen. Plant Pathol. 69:176-185.

14. Kashimoto, K., Sameshima, T., Matsuda, Y., Nonomura, T., Oichi, W., Kakutani, K., Nakata, K., Kusakari, S., and Toyoda, H. 2003. Infectivity of a Japanese isolate of Oidium neolycopersici KTP-01 to a European tomato cultivar resistant to O. lycopersici. J. Gen. Plant Pathol. 69:406408.

15. Kiss, L. 1996. Occurrence of a new powdery mildew fungus (Erysiphe sp.) on tomatoes in Hungary. Plant Dis. 80:224.

16. Kiss, L., Cook, R. T. A., Saenz, G. S., Cunnington, J. H., Takamatsu, S., Pascoe, I., Bardin, M., Nicot, P. C., Sato, Y., and Rossman, A. Y. 2001. Identification of two powdery mildew fungi, Oidium neolycopersici sp. nov. and $O$. lycopersici, infecting tomato in different parts of the world. Mycol. Res. 105:684-697.

17. Kiss, L., Takamatsu, S., and Cunnington, J. H. 2005. Molecular identification of Oidium neolycopersici as the causal agent of the recent tomato powdery mildew epidermics in North America. Plant Dis. 89:491-496.

18. Leach, C. M. 1976. An electrostatic theory to explain violent spore liberation by Drechslera turcica and other fungi. Mycologia 68:63-86.

19. Lebeda, A., and Mieslerová, B. 2002. Variability in pathogenicity of Oidium neolycopersici on Lycopersicon species. J. Plant Dis. Prot. 109:129-141.

20. Lee, S. A., Willeke, K., Mainelis, G., Adhikari, A., Wang, H., Reponen, T., and Grinshpun, S. A. 2004. Assessment of electrical charge on airborne microorganisms by a new bioaerosol sampling method. J. Occup. Environ. Hyg. 1:127-138.

21. Lindhout, P., Pet, G., and van der Beek, H. 1994. Screening wild Lycopersicon species for resistance to powdery mildew (Oidium lycopersicum). Euphytica 72:43-49.

22. Lindhout, P., van der Beek, H., and Pet, G. 1994. Wild Lycopersicon species as sources for resistance to powdery mildew (Oidium lycopersicum): Mapping of the resistance gene $\mathrm{Ol-1}$ on chromosome 6 of $\mathrm{L}$. hirsutum. Acta Hortic. 376:387-394.

23. Matsuda, Y., Kashimoto, K., Takikawa, Y., Aikami, R., Nonomura, T., and Toyoda, H. 2001. Occurrence of new powdery mildew on greenhouse tomato cultivars. J. Gen. Plant Pathol. 67:294-298.

24. Matsuda, Y., Mori, Y., Nishida, M., Sakano, S., Tarumoto, K., Nonomura, T., Nishimura, H., Kusakari, S., and Toyoda, H. 2005. Screening of wild Lycopersicon species for resistance to Japanese isolate of tomato powdery mildew Oidium neolycopersici. Breed. Sci. 55:355-360.
25. Matsuda, Y., Sameshima, T., Moriura, N., Inoue, K., Nonomura, T., Kakutani, K., Nishimura, H., Kusakari, S., Takamatsu, S., and Toyoda, H. 2005. Identification of individual powdery mildew fungi infecting leaves and direct detection of gene expression by single conidium PCR. Phytopathology 95:1137-1143.

26. McCartney, H. A., Bainbridge, A., and Legg, B. J. 1982. Electric charge and the deposition of spores of barley mildew Erysiphe graminis. Atmos. Environ. 16:1133-1143.

27. Mieslerová, B., Lebeda, A., and Chetelat, R. T. 2000. Variation in response of wild Lycopersicon and Solanum spp. against tomato powdery mildew (Oidium lycopersici). J. Phytopathol. 148:303-311.

28. Mitchell, B. W., Buhr, R. J., Berrang, M. E., Bailey J. S., and Cox, N. A. 2002. Reducing airborne pathogens, dust and Salmonella transmission in experimental hatching cabinets using an electrostatic space charge system. Poult. Sci. 81:49-55.

29. Mizuno, A., and Washizu, M. 1995. Biomedical engineering. Pages 653686 in: Handbook of Electrostatic Processes. J. Chang, A. J. Kelly, and J. M. Crowley, eds. Marcel Dekker, New York.

30. Moriura, N., Matsuda, Y., Oichi, W., Nakashima, S., Hirai, T., Nonomura, T., Kakutani, K., Kusakari, S., Higashi, K., and Toyoda, H. 2006. An apparatus for collecting total conidia of Blumeria graminis f. sp. hordei from leaf colonies using electrostatic attraction. Plant Pathol. 55:367-374.

31. Moriura, N., Matsuda, Y., Oichi, W., Nakashima, S., Hirai, T., Sameshima, T., Nonomura, T., Kakutani, K., Kusakari, S., Higashi, K., and Toyoda, H. 2006. Consecutive monitoring of lifelong production of conidia by individual conidiophores of Blumeria graminis f. sp. hordei on barley leaves by digital microscopic techniques with electrostatic micromanipulation. Mycol. Res. 110:18-27

32. Neshev, G. 1993. Powdery mildew (Oidium sp.) on tomatoes in Bulgaria. Phytoparasitica 21:339-343.

33. Nielsen, K. A., Nicholson, R. L., Carver, T. L. W., Kunoh, H., and Oliver, R. P. 2000. First touch: An immediate response to surface recognition in conidia of Blumeria graminis. Physiol. Mol. Plant Pathol. 56:63-70.

34. Nonomura, T., Matsuda, Y., Bingo, M., Onishi, M., Matsuda, K., Harada, S., and Toyoda, H. 2001. Algicidal effect of 3-(3-indolyl)butanotic acid, a control agent of the bacterial with pathogen, Ralstonia solanacearum. Crop Prot. 20:935-939.

35. Noordeloos, M. E., and Loerakker, W. M. 1989. Studies in plant pathogenic fungi-II. On some powdery mildews (Erysiphales) recently recorded from the Netherlands. Persoonia 14:51-60.

36. Olalla, L., and Torés, J. A. 1998. First report of powdery mildew of tomato caused by an Erysiphe sp. in Spain. Plant Dis. 82:592.

37. Pernezny, K., and Sonoda, R. M. 1998. Powdery mildew of field-grown tomato in Florida. Plant Dis. 82:262.

38. Smith, V. L., Douglas, S. M., and LaMondia, J. A. 1997. First report of powdery mildew of tomato caused by an Erysiphe sp. in Connecticut. Plant Dis. 81:229.

39. Vakalounakis, D. J., and Papadakis, A. 1992. Occurrence of a new powdery mildew of greenhouse tomato in Greece, caused by Erysiphe sp. Plant Pathol. 41:372-373.

40. van der Beek, J. G., Pet, G., and Lindhout, P. 1994. Resistance to powdery mildew (Oidium lycopersicum) in Lycopersicon hirsutum is controlled by an incompletely-dominant gene $\mathrm{Ol}-1$ on chromosome 6. Theor. Appl. Genet. 89:467-473.

41. Whipps, J. M., Budge, S. P., and Fenlon, J. S. 1998. Characteristics and host range of tomato powdery mildew. Plant Pathol. 47: 36-48.

42. White, J. F., Jr., Johnston, S. A., Wang, C.-L., and Chin, C.-K. 1997. First report of powdery mildew in greenhouse-grown tomatoes in New Jersey. Plant Dis. 81:227.

43. Wright, A. J., Thomas, B. J., Kunoh, H., Nicholson, R. L., and Carver, T. L. W. 2002. Influences of substrata and interface geometry on the release of extracellular material by Blumeria graminis conidia. Physiol. Mol. Plant Pathol. 61:163-178. 